\title{
EFFICIENT ALGORITHM FOR VERTICAL HANDOVER IN HETEROGENEOUS WIRELESS MOBILE NETWORK
}

\author{
ZAKIRULLAH ${ }^{1}$, SHAHZADA ALAMGIR $^{2}$, ALAMGIR KHAN ${ }^{3}$, SALMAN \\ SALEEM $^{4}$, IMRAN KHAN ${ }^{5}$ \\ ${ }^{1-5}$ University of Engineering and Technology Peshawar, Pakistan \\ ${ }^{1}$ zakirullahafridi@gmail.com, ${ }^{2}$ shehzada.alamgir@ictech.edu.pk \\ 3 alamgir_uet@outlook.com, ${ }^{4}$ salmansaleem@uetpeshawar.edu.pk \\ 5 imrankhan@uetpeshawar.edu.pk
}

\begin{abstract}
Revised February 2017
ABSTRACT. This paper present the new idea of Vertical handover for heterogeneous Wireless Networks, based on different parameters values i.e, available Bandwidth, received signal strength, mean number of request per unit time. Also other parameters such as mean number of calls served per unit time, power deception, power consumption, network condition and duration for mobile station to present in network are observed. Three network selected for the handover, the vertical handover is take place at best resulted network between the available networks. In this article, provoked with facts and figure which done by vertical handoff procedure on mobile nodes but the crucial parameters which is battery power may also consider highly for certain mobile nodes, call blocking probability of networks are define to make decision for network with good quality, for the proposed algorithm experiment results are shown between the available networks and parameters, graphically illustrate the vertical handover to the specific network.
\end{abstract}

Keywords. Vertical handoff, Heterogeneous wireless mobile networks, new call blocking probability

1. Introduction. As we are moving towards expeditious development and rapid evolution in wireless networks, we faced different type of challenges i-e combining a diverse number of networks. The fourth generation $(4 \mathrm{G})$ of mobile communication networks is expected to integrate a possibly huge amount of heterogeneous wireless network in that could be investigated towards the universal seamless access. there will be many challenges in the process of seamless mobility one of the main is efficient vertical scheme availability, that is decision for a mobile point (i.e. mobile cell phone, tab-pc, Laptop) to handover among the various types of networks i.e, cellular, wireless area network (WAN, wide local area network (WLAN) [1].

As we look back to the traditional cellular approach to the communication which also mention with name GSM, the predefine threshold which compare different parameters in specific order is basically used to handle handover decisions [2] the handover are not only cause of ongoing call connections but it can be helpful in order to provide best services package and to fulfill their requirements for stable communication with the comparison to horizontal handover the newly presented vertical handover not only based on the received signal gain which is known as RSS but also the different services i-e class mapping among the handoff-out and handoff-out networks [3] high data rate services (HDS) and Nonpareil global roaming (NGR) eminent fourth generation $4 \mathrm{G}$ from the previous of wireless networks (WN) [4],[5].the $4 \mathrm{~g}$ networking model contains, mobile nodes or handsets terminals connects by different multiple interfaces which will be able to select the best suitable link for access among the all available alternatives. Those ace links consist of IEEE 802.11 access of wireless local area network (WAN) [6]. When we talking about the idea behind connectivity in best way through various networks, a good QoS and also decrease in the call dropping level after unnecessary and wrong handover a phone call in process might be drop or interrupted. The wrong decision of handover cause by unnecessary handover directly affects the QoS makes interruption with ongoing transmission. The more important is the process of handover accurately and seamlessly executes to enhance the QoS. The application of multimedia i-e video streaming, web browsing depend upon good QoS the mandatory is to identify the 
vertical handover quality of service and network performance or network selection. The concept of vertical handover insure the quality by reduction in effects know by Ping-Pong, to reduce interruption in process call at the time of handover, enhance the system throughput [7]. Several algorithms are based on method of classical network technique [8] and some of them are based on Markova outcomes process [9]. The important parameters are following; these are examined in vertical handoff decision for the proposed scheme to develop. The big challenge for the upcoming generation which is IP-based network is seamless and fast handover which is in notice to support the real-time application of high speed multimedia. The requirement for this application is packet loss, small handover latency and also high data rate for transmission over wireless medium [10].Tamil jetchelvy et al [11] have proposed a dynamic Numerous Characteristic decision mechanism which based on the Importance of Traffic flow levels for static Bit rate Along with Flexible Bit Rate in order to reduce the process for handover. with this mechanism, offered flawless handover refence to MIH IEEE 802.21 standard. Most of the time vertical handoff decision depend upon the available bandwidth each and every wireless access network, the available ISP (Internet Service Provider) charge to that specific network connection, the requirements for power usage, and the battery current status in mobile device. The operation for vertical handoff should contribute testimonial for the users of mobile device, acquire a low level control overhead, and also control the connections which cause packet loss and minimized the transfer delay as well. Commonly the process which takes part in Vertical handover can be classified into three stages [12], [13], namely handoff decision, system discovery and the last one is handoff execution. Throughout the 1st system discovery phase, the terminals of mobile device equipped with various interfaces have to examine that which networks is suitable for use and the available services in that specific network. Probably the networks advertise also different services for the supported data rates. During the 2nd phase handoff decision, the mobile node search for the network to connect. This decision will depend upon different parameters i-e the bandwidth available, jitter, delay, access cost, transmit power, the user's preferences and current battery status of the mobile device. During the 3rd and last phase of handoff execution, in this phase the need of re-routed the new network from the existing network connections with in a seamless manner. In This phase we also have authorization and authentication, and user's context information to be transfer as well. Although in recent literature a variety of vertical handoff decision scheme have been proposed [14]-[17]. In section 2 we briefly explain the system model. In Section 3 we lightly touch the background knowledge regarding this topic. In section 4 contains the proposed algorithm explanation. In section 5 experimental results are shown and discussed. Finally In section 6 we conclude the work and conclusion.

2. SYSTEM MODEL. In our work we assume 3 networks the 1st one is WLAN, 2nd is cellular GSM/DCS and 3rd and last one is WiMAX these are different from each other the 1stand last one is IP base and the other one is circuit switched base with different frequency, we analyze different parameters of these networks and the proposed model will decide to vertically handover to the other best network in case of weak signal level or in case of no available network.

3. WLAN. Wi-Fi (wireless fidelity) is a wireless network operates in local area over a short range. According to IEEE it is standardize at IEEE 802.11, the basic aims to provide connectivity to the different devices such as laptops, PDAs, personal computers, printers and smart phones. The IEEE 802.11 terms allow connectivity in two modes the $1^{\text {st }}$ one is ad hoc mode and the other is infrastructure mode. In ad hoc mode there is no need of access point support, device directly communicate with each other. In infrastructure mode we need access point support the Wi-Fi node communicate over the access point according to the structure of IEEE 802.11 below in figure is hierarchical. 


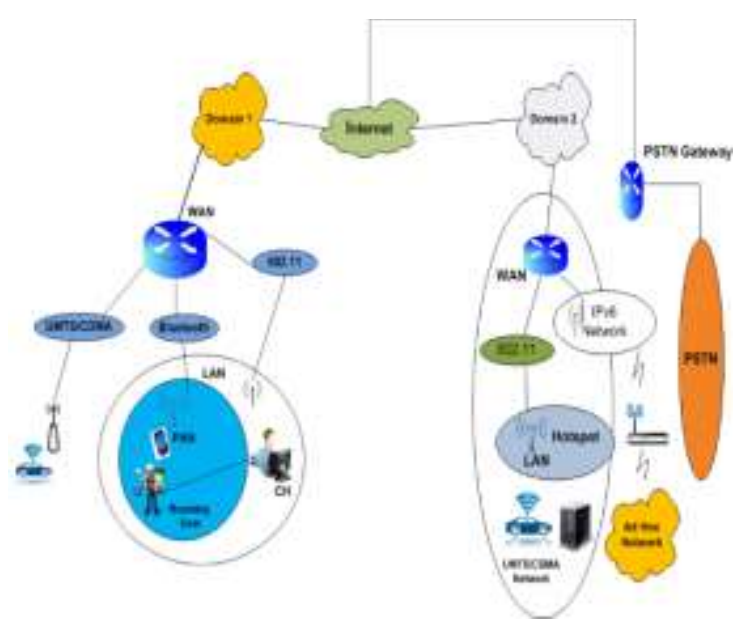

Figure: 1 Wireless internet Roaming scenario in heterogeneous network

The basic element in this scenario is basic service set (BSS), contains the number of station in group, comparatively covered are as much cover by access point.

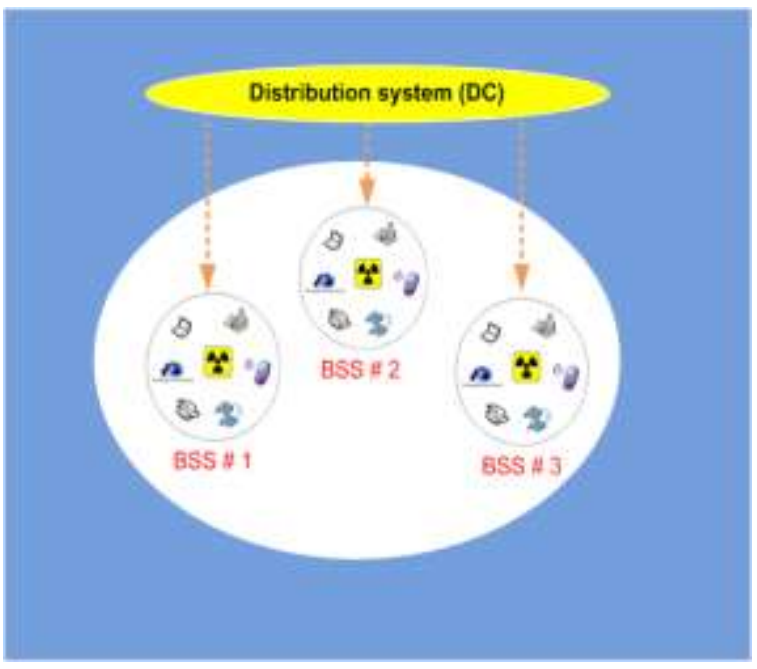

Figure 2.Wi-Fi infrastructure mode

A.WiMAX. Usually known as Worldwide Interoperability for Microwave Access this is long range wireless network. Cording to IEEE standard it is standardized at 802.16. (WiMAX) is a Wireless Metropolitan Access Network (WMAN). WiMAX is high Speed Data network and also covering the large area as compare to Wi-Fi, Support mobile broadband and fixed node access. In This Article we focus on Mobile broadband (WiMAX), It is illustrate in figure 3, contains on 3 steps: The user's device which known as mobile station (MS), The $2^{\text {nd }}$ is Connectivity Service Network (CSNW) is the back bone of WiMAX network which make possible the connectivity of IP to the MS, the last one is Access Service Network (ASNW) is work for Radio access and contain one or more than one base station also ASNW Gateways (ASNW-GW). 


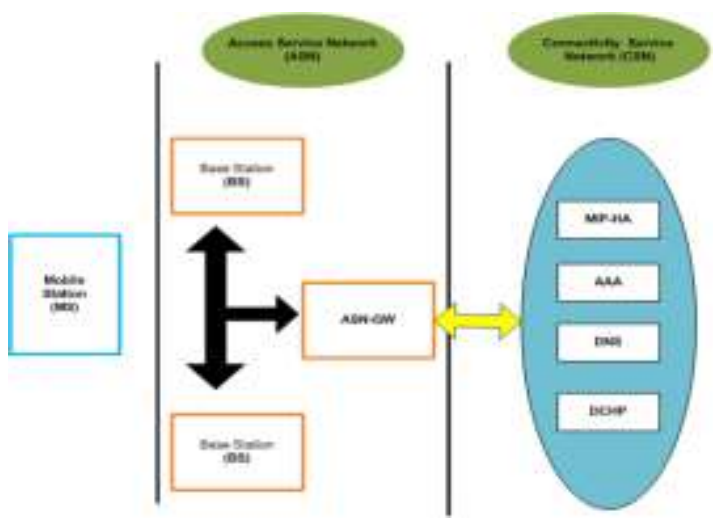

Figure 3.WiM architecture

B. GSM. Global system for mobile communication, the circuit switch communication system which operate at $900 \mathrm{Mhz}$ and $1800 \mathrm{Mhz}$,use for voice data communication based on wireless, usually affect by environmental effects along with systematic issues, In order to achieve goals need to provide good quality of service for this is only when the required parameters are hit the predefine threshold ,If the values are less then threshold it may require to search nearby network with good values of these parameters and move on to that network, this term known as vertical handover .

4. Process Handover Management. When we moving from one access link (access router or base station) to another, to maintain connection continuous for active mobile terminal in mobility scenario, this procedure known as Handover management, we divide Handover management in three stages:

- Handover informative: is use for collecting of information Data to desire initiate handover. This term also define as system discovery or handover initiation stage.

- Handover conclusion: is use to decide to how and when we can execute the handover this just indicate about the status of handover requirements that need to perform handover, also choosing the finest access link accessible and by openhanded directions to the subsequently stage, i.e, handover implementation as well recognized as network selection or classification .

- Handover implementation: is stage where Handover take place according to system requirements and best system selection based on handover algorithm.

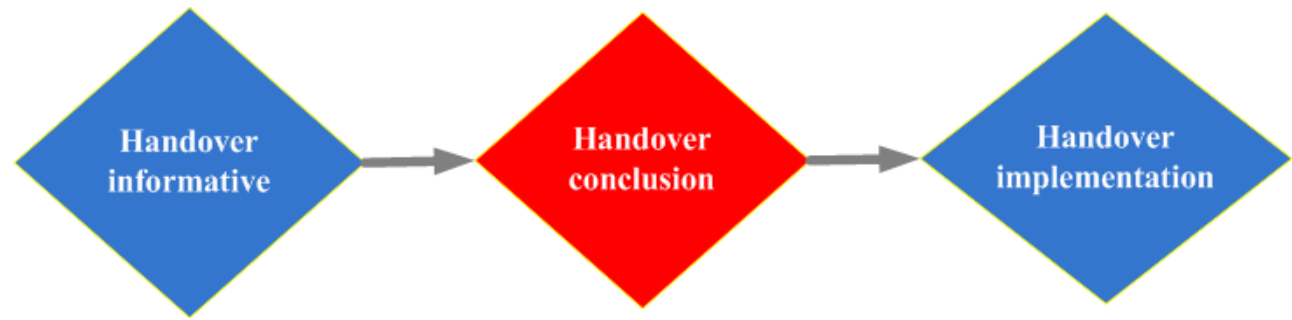

Figure 4.Handover management Process

Here we go with the stage 1 Handover informative, in this part we collect the basic information which is required to handle vertical handover and these are given below. We define the numbers of total networks $\mathrm{N}=$ Number of Networks Presently available for evaluation. In $1^{\text {st }}$ Stage now we define the all available networks values, here also at top we have available bandwidth of the current connected network and this is given below.

ßi $=1800 \mathrm{MHz}$ 
Here $B \mathrm{i}$ is the current connected network bandwidth.

Current connected network received signal level in $\mathrm{dB}$

Řsli $=-55 \mathrm{~dB}$

Řsli $=$ Ëì̌p $-\grave{\eta}$

EIRP $(\mathrm{dBm})$ effective isotropic Radiated power \& $\eta$ is Path loss and EIRP is equal to

Ëĭ̌p $=\mathrm{Pt}+\mathrm{Ga}$

$\mathrm{Pt}$ is transmit power and Ga is Antenna Gain and

Path-loss is defined below

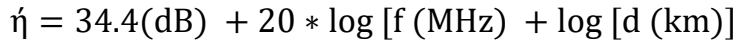

Where 34.4 is proportional, constant $\mathrm{f}$ is Frequency of MS and d is distance of MS.

Estimated Time MN will stay in the network coverage

$\mathrm{Fi}=10 \mathrm{~ms}$

Transmit power of the currently connected network

$\mathrm{p} o=30 \mathrm{dBm}$

The mean number of Request arrival per unit time,

$£=10$

Where $£$ is define as

$€=$ calls /minute

Mean number of Call served per unit time

$\sigma=3$

Now the Network Dependent Weights to the following parameters

Power consumption of MS $=-33 \mathrm{dBm}$

Network condition $=1$

Table1: Network obtain values

\begin{tabular}{|c|l|l|l|l|}
\hline $\begin{array}{l}\text { Serial } \\
\text { No: }\end{array}$ & Parameters & $\begin{array}{l}\text { Value } \\
\text { for } \\
\text { Network } \\
\text { ID '1' }\end{array}$ & $\begin{array}{l}\text { Value } \\
\text { for } \\
\text { Network } \\
\text { ID '2' }\end{array}$ & $\begin{array}{l}\text { Value } \\
\text { for } \\
\text { Network } \\
\text { ID '3' }\end{array}$ \\
\hline 1. & $\begin{array}{l}\text { Available } \\
\text { Bandwidth }\end{array}$ & 1800 & 2400 & 5000 \\
\hline 2. & $\begin{array}{l}\text { Received } \\
\text { signal level }\end{array}$ & -55 & -70 & -60 \\
\hline 3. & $\begin{array}{l}\text { Estimated } \\
\text { Time for MS }\end{array}$ & 10 & 15 & 10 \\
\hline 4. & $\begin{array}{l}\text { Power } \\
\text { Dissipation } \\
\text { NW }\end{array}$ & 30 & 40 & 30 \\
\hline 5. & Lambda & 10 & 5 & 10 \\
\hline 6. & $\begin{array}{l}\text { Call served } \\
\text { per unit } \\
\text { time }\end{array}$ & 3 & 3 & 4 \\
\hline 7. & $\begin{array}{l}\text { Power } \\
\text { consumption } \\
\text { of MS }\end{array}$ & -33 & -25 ' & -30 \\
\hline 8. & $\begin{array}{l}\text { Network } \\
\text { Conditions }\end{array}$ & 1 & 1 & 1 \\
\hline & & & & \\
\hline
\end{tabular}


Similarly, we take values for other two networks. In $2^{\text {nd }}$ Stage Handover Decision, we compare these parameters values with predefine threshold values. The Threshold values are those values which define the handover decision and also the best network for handover. If there any network have values grater then define threshold values, user will jump to that network and continue communication with good quality. Here we have the $1^{\text {st }}$ parameter value for threshold which is given below

$ß=1800 \mathrm{MHz}$

$\mathrm{Bi}$ is the current available bandwidth threshold for communication values are in MHZ

Řsl $=-70 \mathrm{~dB}$

Received signal level is the signal strength which measure at receiver side and its values will be negative always unit is $\mathrm{dBs}$

RSL Range

Up to $-65 \mathrm{dBm}$ : Excellent

-75 to -95 : Normal

-65 to $75:$ Good

$<95$ : Worst

$\mathrm{F}=5 \mathrm{~ms}$

This term define Estimated Time MS will stay in the network coverage

$\mathrm{P} o=10 \mathrm{~dB}$

The above is threshold transmit power

Table2: Predefine Threshold values

\begin{tabular}{|c|c|c|}
\hline Serial & Parameter & Threshold \\
\hline 01. & $\begin{array}{l}\text { Current Available } \\
\text { Bandwidth } \\
\text { (B) }\end{array}$ & 1800 \\
\hline 02. & $\begin{array}{l}\text { Received Signal level } \\
\text { (RSL) }\end{array}$ & -70 \\
\hline 03. & $\begin{array}{c}\text { Estimated Time MS will be } \\
\text { in present network } \\
(\mathrm{T})\end{array}$ & $5 \mathrm{~ms}$ \\
\hline 04. & Tx Power & 10 \\
\hline
\end{tabular}

In this stage we evaluates the initial step decision function to find the suitable, Set of networks out of the available networks with values greater Than threshold

$\delta=\tau-\Phi$

Where $\tau$ is threshold value and $\Phi$ is the available network value.

$\omega=(\mathrm{B} \delta)>0) *(\operatorname{RSL} \delta)>0) *(\mathrm{~T} \delta)>0) *(\mathrm{~V} \delta)>0) *(\mathrm{P} \delta)>0)$; (17) 
$\omega=0$

Mean no network available for vertical handover. The Greater value of $\omega$ will find the available networks, on the bases of Dynamic call blocking probability vertical handover take place. The Dynamic call blocking probability is given below

$\grave{\mathrm{l}}=£ / \sigma$

$\mathrm{DCBP}=(\mathrm{i} . \wedge(ß) / ß$ !

5. Simulation Outcomes: After implementation, we got the vertical handover to that specific site Id no 3, according to the network parameters from these simulations we get the points which contribute in vertical handover, the available bandwidth is major factor and all others are also important such as DCBP. The below figure shows the different network number on X-axis and New Dynamic call blocking probability on the Y-axis, the vertical handover is perform to the network ID 2 which is clearly shown, where we have 0 Call blocking probability
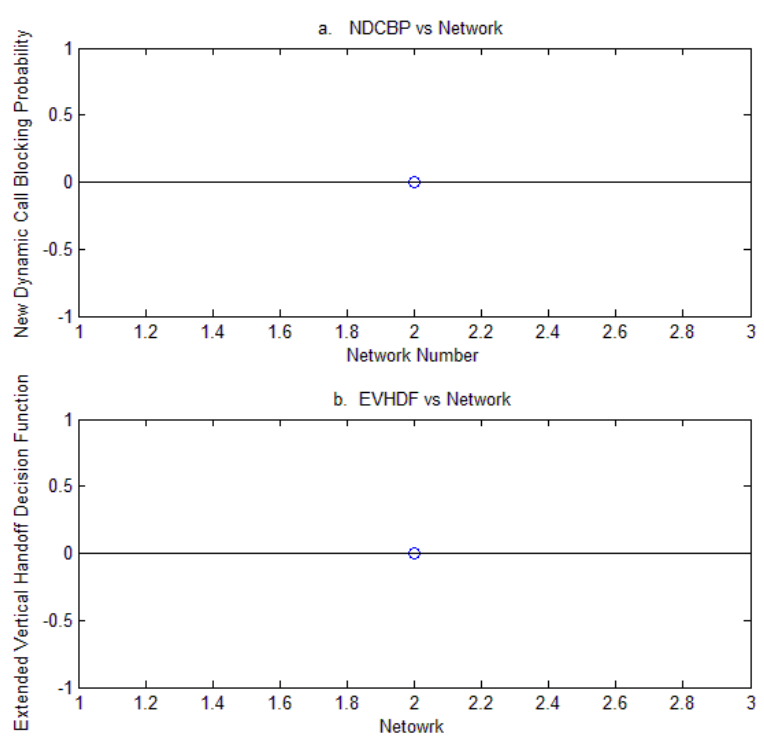

Figure 5. Network number vs call blocking probability

In this work we analyze three terms the 1st one is Vertical handover between seamless network, which perform in case where we no access to the seam NW ,the values of network parameters compute the data for new network with good number of network parameters values, The 2nd parts of Article describe the Extended vertical handover function which is purely based on Call dynamic blocking probability, according to call blocking probability the network analysis take place and handover vertically to the desire Network with good parameters values but also DCBP values .

6. Conclusion: This work is based on Vertical handover informative and handover implementation. The aforementioned process depends upon available networks. Secondly, the work is related with the predefine threshold parameters. The vertical handover takes place in seamless network, but the parameter values such as RSS, available bandwidth, lambda (of the new network) must be good and the DCBP is key factors in these values. The different parameters play role in vertical handover process. We consider three different networks to more accurately analyze the vertical handover process. The realistic approach used to identify the preferable network with the high values of network parameters. DCBP is related to the available bandwidth as well as the value of lambda. 


\section{REFERENCES}

[1] Nasser, N., Hasswa, A., \& Hassanein, H. (2006). Handoffs in fourth generation heterogeneous networks. IEEE Communications Magazine, 44(10), 96-103.

[2] Hasswa, A., Nasser, N., \& Hassanein, H. (2007). A seamless context-aware architecture for fourth generation wireless networks. Wireless Personal Communications, 43(3), 1035-1049.

[3] Pawar, P., Wac, K., Van Beijnum, B. J., Maret, P., van Halteren, A., \& Hermens, H. (2008, March). Context-aware middleware architecture for vertical handover support to multi-homed nomadic mobile services. In Proceedings of the 2008 ACM symposium on Applied computing (pp. 481-488). ACM.

[4] Dekleva, S., Shim, J. P., Varshney, U., \& Knoerzer, G. (2007). Evolution and emerging issues in mobile wireless networks. Communications of the ACM, 50(6), 38-43.

[5] Ghaderi, M., \& Boutaba, R. (2006). Call admission control in mobile cellular networks: a comprehensive survey. Wireless communications and mobile computing, 6(1), 69-93.

[6] Deng, D. J., \& Yen, H. C. (2005). Quality-of-service provisioning system for multimedia transmission in IEEE 802.11 wireless LANs. IEEE Journal on Selected Areas in Communications, 23(6), 1240-1252.

[7] ] Enrique Stevens-Navarro and Vincent W.S. Wong, Comparison between Vertical Handoff Decision Algorithms for Heterogeneous Wireless Networks, 2006 IEEE.[6]. Mingxin Li, A Multi-step Vertical Handoff Mechanism for Cellular Multihop Networks, PM2HW2N'07, October 26, 2007, Chania, Crete Island, Greece. Copyright 2007 ACM.

[8] Singhrova, A., \& Prakash, N. (2007, September). A review of vertical handoff decision algorithm in heterogeneous networks. In Proceedings of the 4th international conference on mobile technology, applications, and systems and the 1st international symposium on Computer human interaction in mobile technology (pp. 68-71). ACM.

[9] Joe, I. (2010). Sungchan Hong College of Information and Communications Hanyang University Seoul. Korea A Mobility-based Prediction Algorithm for vertical handover in hybrid wireless network.

[10] Singhrova, A., \& Prakash, N. (2012). Vertical handoff decision algorithm for improved quality of service in heterogeneous wireless networks. IET communications, 6(2), 211-223.

[11]R. Tamijetchelvy, G. Sivaradji and P. Sankaranarayanan, "Dynamic MAPT Approach for Vertical Handover Optimization in HeterogeneousNetwork for CBR and VBR QoS Guarantees",International Conference on Information and Communication Technologies (ICICT),pp: 1164-1172,20 15.

[12] McNair, J., \& Zhu, F. (2004). Vertical handoffs in fourth-generation multinetwork environments. IEEE Wireless Communications, 11(3), 8-15.

[13] Chen, W. T., Liu, J. C., \& Huang, H. K. (2004, July). An adaptive scheme for vertical handoff in wireless overlay networks. In Parallel and Distributed Systems, 2004. ICPADS 2004. Proceedings. Tenth International Conference on (pp. 541-548). IEEE.

[14]Zhu, F., \& McNair, J. (2004, March). Optimizations for vertical handoff decision algorithms. In Wireless Communications and Networking Conference, 2004. WCNC. 2004 IEEE (Vol. 2, pp. 867-872). IEEE.

[15] Chen, W. T., \& Shu, Y. Y. (2005, March). Active application oriented vertical handoff in next-generation wireless networks. In IEEE Wireless Communications and Networking Conference, 2005 (Vol. 3, pp. 1383-1388). IEEE.

[16]Zhang, W. (2004, March). Handover decision using fuzzy MADM in heterogeneous networks. In Wireless communications and networking conference, 2004. WCNC. 2004 IEEE (Vol. 2, pp. 653-658). IEEE.

[17] Song, Q., \& Jamalipour, A. (2005, May). A network selection mechanism for next generation networks. In IEEE International Conference on Communications, 2005. ICC 2005. 2005 (Vol. 2, pp. 1418-1422). IEEE. 